\title{
RESULTADOS DE LA INVESTIGACIÓN APLICADA DEL ANALISIS DE CONTENIDO EN LA COMUNICACIÓN PUBLICITARIA GRÁFICA
}

José Jesús Vargas Delgado: Decano Universidad Europea de Canarias. España. jjesus.vargas@uem.es

\section{RESUMEN}

Análisis de contenido como método para analizar las principales tendencias creativas en publicidad eficiente en la comunicación publicitaria gráfica, en la categoría de vehículos y accesorios, en el festival de cine publicitario de San Sebastián desde el año 1993, hasta 2004. Nuestra investigación aplicada se encuentra focalizada en los efectos de un estudio experimental en el que examina en profundidad y de forma cualitativa la deconstrucción de la comunicación publicitaria visual eficiente y ganadoras. Definición de la esencia constructiva de los mensajes comunicativos visuales. Para ello hemos desarrollado un método analítico de deconstrucción cualitativo a través del análisis de contenido de la eficiencia comunicativa aplicada a los mensajes publicitarios gráficos. Dado que nuestro principal objetivo es determinar, e investigar, la eficiencia de la publicidad gráfica y sus principales tendencias creativas, es necesario desembocar inexorablemente en el análisis de contenido, como camino para alcanzar nuestras metas investigadoras. Sobre todo con el análisis de contenido vamos a analizar las principales tendencias de la publicidad gráfica en el Festival de San Sebastián en la categoría de vehículos y accesorios. A través de un longitudinal proceso de análisis de las piezas ganadoras de cada año en el Festival de publicidad de San Sebastián podremos lo que funciona como un corte intenso para ver las características específicas de cada pieza ganadora durante esos años.

PALABRAS CLAVE: Dirección - Cuadrante - Color - Iconicidad - Formato

\footnotetext{
${ }^{1}$ Autor correspondiente:

Dr. José Jesús Vargas Delgado: Decano de la Universidad Europea de Canarias. España.

Correo: jjesus.vargas@uem.es
} 


\title{
Results Analysis Applied Research Communication Content in Advertising Graphics
}

\begin{abstract}
Content analysis as a method to analyze the main trends efficient advertising creative advertising communication graph, in the category of vehicles and accessories in the advertising film festival San Sebastian from 1993 until 2004. Our applied research is focused on the effects of an experimental study that examines in depth and qualitatively the deconstruction of visual advertising communication efficient and winning. Defining the constructive essence of visual communication messages. We have developed an analytical method of deconstruction through qualitative content analysis of communicative efficiency applied to advertising graphics. Since our main objective is to identify, and investigate the efficiency of display advertising and its major creative trends, it is necessary to lead inexorably content analysis as a path to achieve our research goals. Especially with content analysis we will analyze the main trends of display advertising in the San Sebastian Festival in the category of vehicles and accessories. Through a process of analyzing longitudinal winning pieces each year at the festival of San Sebastian can advertise what works as a deep cut to see the specifics of each winning piece during those years.
\end{abstract}

KEYWORDS: Balance - Quadrant - Color - Iconicity - Format

\section{INTRODUCCIÓN}

Análisis de contenido como método para analizar las principales tendencias creativas en publicidad eficiente en la comunicación publicitaria gráfica, en la categoría de vehículos y accesorios, en el festival de cine publicitario de San Sebastián desde el año 1993, hasta 2004. Nuestra investigación aplicada se encuentra focalizada en los efectos de un estudio experimental en el que examina en profundidad y de forma cualitativa la deconstrucción de la comunicación publicitaria visual eficiente y ganadoras. Definición de la esencia constructiva de los mensajes comunicativos visuales. Para ello hemos desarrollado un método analítico de deconstrucción cualitativo a través del análisis de contenido de la eficiencia comunicativa aplicada a los mensajes publicitarios gráficos. Dado que nuestro principal objetivo es determinar, e investigar, la eficiencia de la publicidad gráfica y sus principales tendencias creativas, es necesario desembocar inexorablemente en el análisis de contenido, como camino para alcanzar nuestras metas investigadoras. Sobre todo con el análisis de contenido vamos a analizar las principales tendencias de la publicidad gráfica en el Festival de San Sebastián en la categoría de vehículos y accesorios. A través de un longitudinal proceso de análisis de las piezas ganadoras de cada año en el festival de publicidad de San Sebastián podremos lo que funciona como un corte intenso para ver las características específicas de cada pieza ganadora durante esos años. Presentamos por lo tanto un análisis profundo desde el unto de vista cualitativo de piezas que han sido auténticas referencias creativas ganadoras de festivales publicitario. A partir de

Revista de Comunicación de la SEECI. (Noviembre, 2013). Año XV (32), 41-72 
esa rigurosa y cualitativa selección podremos obtener una fotografía nítida de los elementos esenciales desde el contenido de las piezas que han sido realmente eficaces en una atmósfera publicitaria durante una trayectoria temporal.

\section{METODOLOGÍA}

Dado que nuestro principal objetivo es determinar, e investigar, la eficiencia de la publicidad gráfica y sus principales tendencias creativas, es necesario desembocar inexorablemente en el análisis de contenido, como camino para alcanzar nuestras metas investigadoras. Sobre todo con el análisis de contenido vamos a analizar las principales tendencias de la publicidad gráfica en el Festival de San Sebastián en la categoría de vehículos y accesorios. El centro neurálgico de nuestra investigación es la comunicación publicitaria gráfica, para lo cual el análisis de contenido se conforma ideal para su aplicación. Pero no solamente la idoneidad del método ha determinado la utilización del análisis de contenido. La búsqueda de una técnica de investigación para la descripción objetiva, sistemática y cuantitativa del contenido de la comunicación, ha conformado el otro pilar que ha fundamentado nuestra elección final. Es un método para analizar objetiva y científicamente los mensajes publicitarios gráficos. Es una técnica de estudios específicos de comunicación que utiliza el método hipotéticodeductivo. Analizaremos los soles de oro; las piezas creativas ganadores del Festival publicitario de San Sebastián en España desde el año 1993 hasta el 2003. Un análisis de contenido que pasa por la introspección investigadora a través de cuatro palancas o criterios analíticos: Contraste de color, ubicación de la imagen en el cuadrante, dirección y formato en la imagen.

\section{ANÁLISIS Y DISCUSIÓN}

\subsection{Análisis de contenido de la pieza gráfica premiada con el sol de oro del Festival Publicitario de San Sebastián de 1993.}

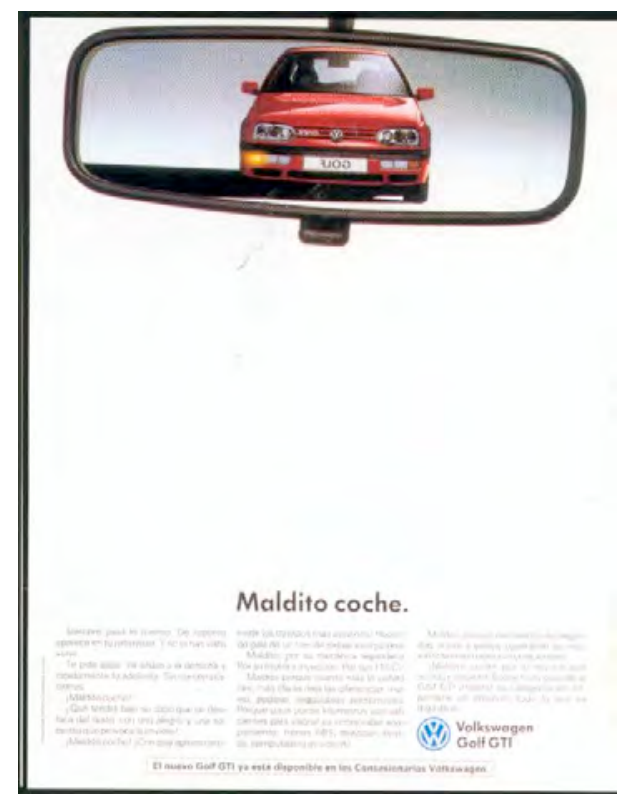




\subsubsection{Contraste de color.}

El color que se ha elegido para el vehículo es el rojo. El color rojo genera una serie de significados siempre relacionados con la actividad. Es un color que se acerca y nos invade hasta el punto de activar nuestra atención. En este caso es el vehículo el que nos invade. Es un color que se asocia con alegría, pasión, emoción, libertad... Es la apuesta del receptor por este tipo de producto. El color rojo es el idóneo para narrar una situación alarmante y de peligro. En este caso la envidia tiene un color; ese es el color rojo. El color que predomina en la pieza es el blanco del fondo de la misma. Éste representa el $46,67 \%$. El color blanco de fondo, y con este porcentaje tan alto, la lectura suele ser más reposada y suele ayudar a la memoria de la pieza y a la atención de la pieza.

\subsubsection{Ubicación de la imagen en el cuadrante.}

La imagen esta ubicada en la parte superior de la pieza, y claramente es el primer elemento sobre el que se dirige la mirada del receptor.

Concretamente la imagen de la pieza ocupa un 26,66\%. De esta manera el

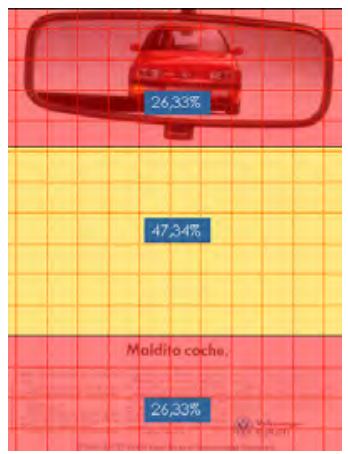

protagonismo entre la imagen y el texto principal y secundario es similar:

\subsubsection{La dirección.}

La dirección que siguen los elementos de la pieza es claramente: vertical-horizontal.

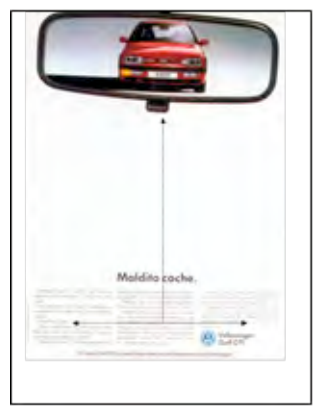

Dicha estructura genera estabilidad y solidez en la lectura del receptor. Disminuye por lo tanto la capacidad de inestabilidad y dinamismo en el mensaje. El contenido de la 
pieza demanda una estructura relajada y firme como ha sido elegido por los creativos de la marca.

\subsubsection{Formato de la imagen.}

La imagen dispone un ratio largo, pero la disposición de los elementos de la pieza no genera movimiento ni dinamismo. El objetivo estético de la pieza pasa por la calma y la tranquilidad.

\subsection{Análisis de contenido de la pieza gráfica premiada con el sol de oro del Festival Publicitario de San Sebastián de 1994.}

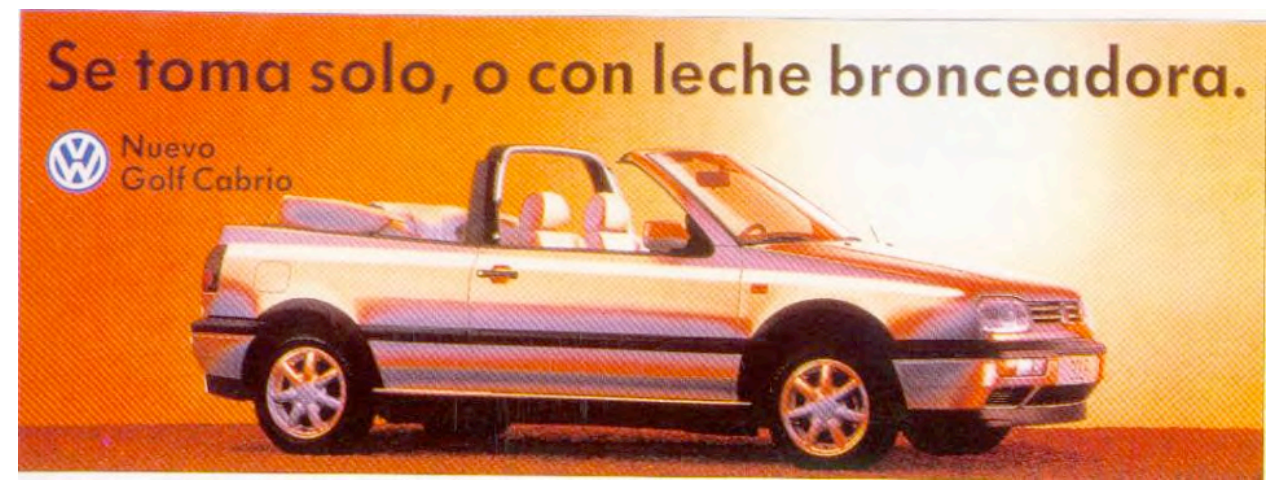

\subsubsection{Contraste de color.}

Los colores cálidos son los elementos cromáticos predominantes en la pieza. Según Bivier, el color anaranjado mantiene connotaciones de cualidades domésticas, expresa seguridad y confort. Y lo más elemental en función de nuestra pieza es la idea de que estimula la presencia del sol. A medida que la lectura de la pieza gira a la izquierda el anaranjado se va aclarando a tonos amarillentos. El amarillo es el vínculo entre el sol dador de vida y el oro. En su forma más pura, el amarillo indica calor, imaginación y cierta frivolidad (Briever).

\subsubsection{Ubicación de la imagen en el cuadrante.}

3/4 partes de la pieza está ocupada por la imagen, aunque de cara al entendimiento de la pieza, sea el texto el que tiene el mayor porcentaje de protagonismo. 


\subsubsection{La dirección.}

La dirección que siguen los elementos de la pieza es claramente: vertical-horizontal:

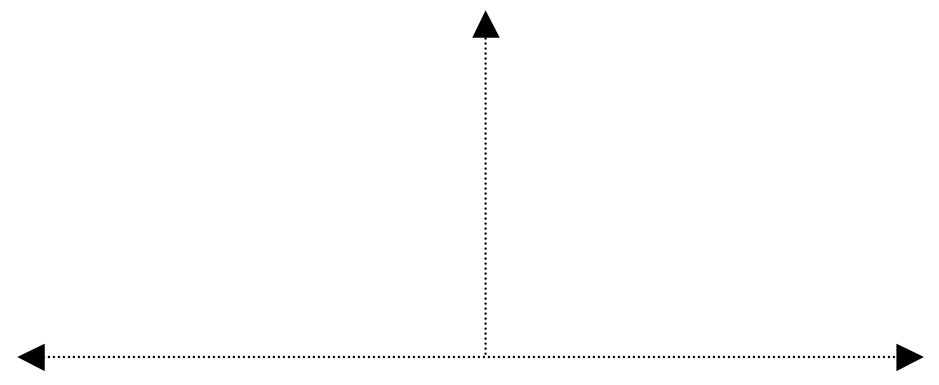

Dicha estructura genera estabilidad y solidez en la lectura del receptor. Disminuye por lo tanto la capacidad de inestabilidad y dinamismo en el mensaje. El contenido de la pieza demanda una estructura relajada y firme como la elegida por los creativos de la marca.

\subsubsection{Formato de la imagen.}

La imagen dispone un ratio largo, pero la disposición de los elementos de la pieza no genera movimiento ni dinamismo. El objetivo estético de la pieza pasa por la calma y la tranquilidad.

\subsection{Análisis de contenido de la pieza gráfica premiada con el sol de oro del Festival Publicitario de San Sebastián de 1995.}

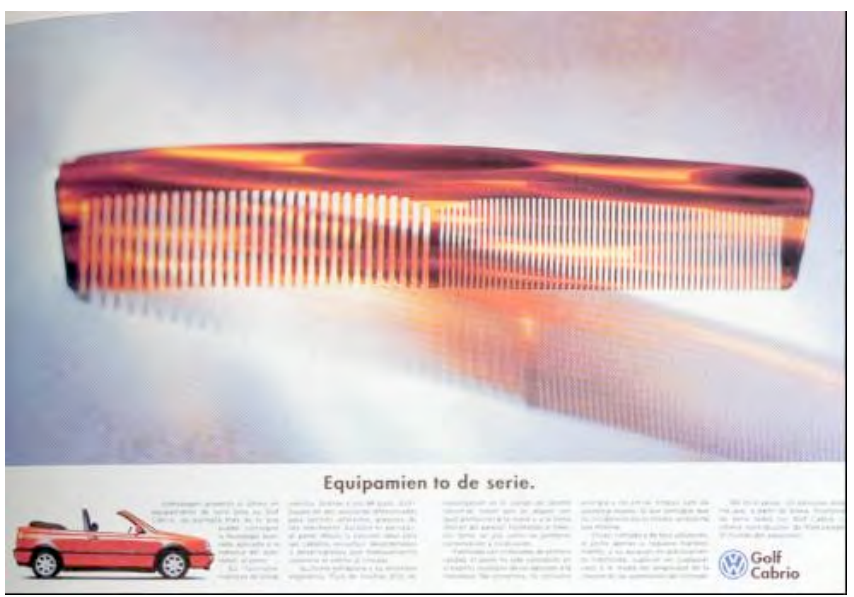

\subsubsection{Contrate de color.}

Existen tres colores actuando de figura, y dos que actúan de fondo. Con respecto a los colores que actúan de figura, podemos diferenciar los siguientes colores:

Marrones: Son diferentes tonos de marrones y anaranjado. Son los colores que tiene la primera imagen de la pieza: el peine. 
El significado que tiene este color está en dicha línea. Según Bivier es el color de las cualidades domésticas, expresa seguridad y confort. Es un color cálido oscuro. Los colores cálidos crean una sensación de acercamiento de la figura al espectador. Pero un acercamiento sosegado.

El rojo del coche mantiene un tono muy en la línea del color del peine, aunque se trata de un rojo. Se acerca, avanza a nosotros a pesar de tener muy poca superficie. Acapara y mantiene la atención, a pesar de su tamaño. Es un color que se asocia con alegría, pasión, emoción, libertad... Es la apuesta del receptor por este tipo de producto.

El tercer color-figura es el azul. El azul lo encontramos, aunque en pequeñas dimensiones, en el logotipo de la marca Volkswagen. Es un color frío que inspira confianza y seguridad, pero distancia con respecto al receptor. Es un color muy apropiado para una marca de la solidez de Volkswagen. No es un color que predomine en la pieza.

Debemos considerar figura al cuerpo de texto. Su color negro es uno de los más utilizado, sobre fondo blanco. Junto a éste se utiliza también muy frecuentemente el texto de blanco sobre fondo negro. En función de la estructura de esta pieza entendemos que el color del texto negro sobre el fondo es mucho más apropiado debido al color del peine y su fondo blanco.

Los colores del fondo mantienen una perspectiva muy parecida. Por un lado tenemos el color de fondo sobre el que se posa el peine. Es un color predominantemente blanco con tonos azules muy leves. El mínimo y frío tono azul del fondo mezclado con el blanco transmite una reposada tranquilidad que favorece la posición de la figura del peine. El cuerpo de texto en negro se posa sobre un fondo blanco. Éste genera tranquilidad, y la plena predisposición para la lectura de texto en color negro.

\subsubsection{Ubicación de la imagen en el cuadrante.}

La estructura de la ubicación de la imagen es la siguiente:

Siguiendo las leyes de lectura de imagen de la cultura occidental, la imagen se inicia con el peine, pasa por el texto y gira a la izquierda, a la imagen del coche. Finalmente la lectura gira desde éste último punto hasta el logotipo de la marca Volkswagen. 


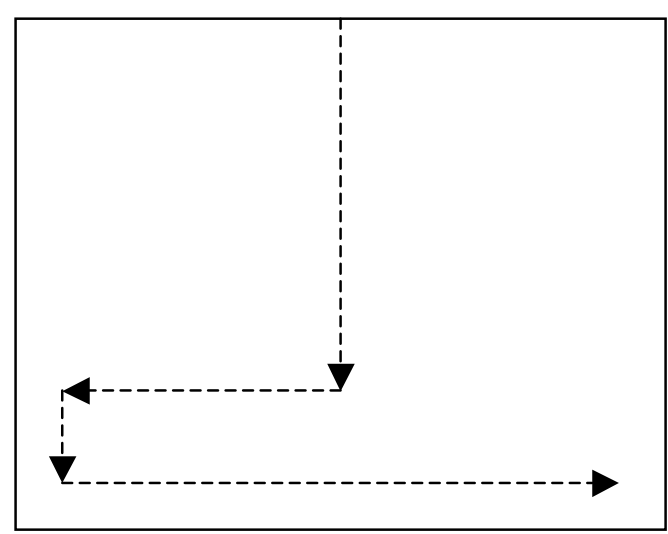

\subsubsection{La dirección.}

El anuncio mantiene una dirección claramente horizontal-vertical.

La dirección horizontal-vertical genera estabilidad y escasez de dinamismo. La intención primordial de la pieza no es provocar a través de la estructura.

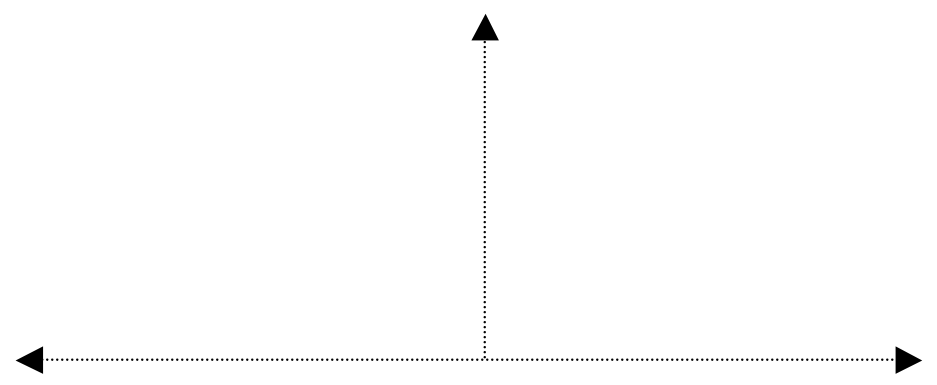

\subsubsection{Formato de la imagen.}

El ratio es la proporción que existe entre los dos lados de la composición. Desde este punto de vista el ratio de la imagen es corto. El ratio corto es esencialmente descriptivo y es más difícil crear el movimiento. Éste es uno de los factores que influyen en que la pieza no tenga ritmo.

\subsection{Análisis de contenido de la pieza gráfica premiada con el sol de oro del} Festival Publicitario de San Sebastián de 1996.

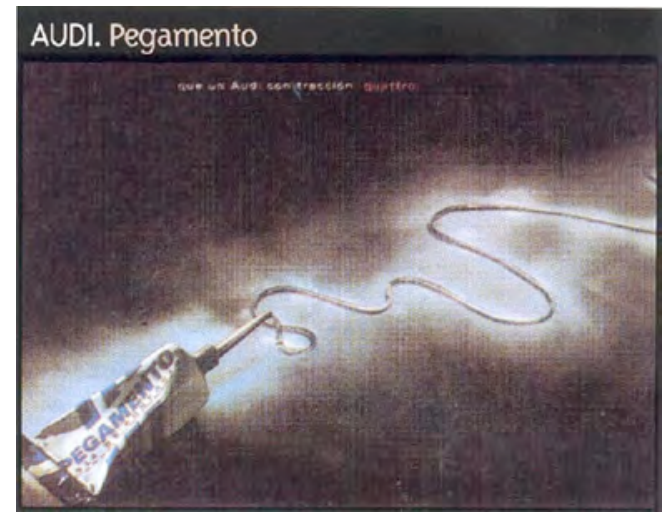




\subsubsection{Contrate de color.}

Antes de comenzar a analizar el color en la pieza es importante señalar que el tono predominante en la pieza es el blanco y negro. En toda la pieza se juega con tonos blancos y grises. Tanto del pegamento, estela y luminosidad del pegamento. El único elemento que rompe con la hegemonía de los tonos blanco y negros es el color rojo del nombre del modelo del coche publicitado: quattro.

Con respecto a la figura, tenemos el bote o envase del pegamento ubicado en la zona inferior izquierda del cuadrante de la pieza. En dicho envase predominan los tonos blancos y luminosos. El blanco es asociado con el día, el nacimiento, claridad y estabilidad absoluta. En ciertos casos, de acuerdo con Lüscher, el blanco puede significar refinamiento y delicadeza. Es el nacimiento de una característica que puede generar claridad en las decisiones del conductor.

Encontramos algunas porciones de tonos grises sobre la superficie del envase de pegamento. Son tonos que nos van a permitir jugar con la misma tonalidad de la muestra de pegamento derramado por la superficie de la pieza. $Y$ como explicaremos posteriormente, dicho tono permite generar analogías cono los tonos de la una carretera convencional.

La estela de pegamento que representa la sinuosidad de la carretera está reflejada con un tono gris. Un tono gris con diferentes graduaciones de brillo, a medida que la estela toma las diferentes curvas por la pieza. El tono gris de la estela es una continuación de alguno de los tonos del bote o envase del pegamento. Es un tono que representa claramente el color gris del asfalto.

El texto del anuncio, mantiene casi en su totalidad un tono blanco. Es el mejor tono en función del fondo negro y de los juegos de contraste de toda la pieza. Decimos casi, porque el nombre del modelo de la marca: quattro, tiene un color rojo que rompe absolutamente con toda la estructura cromática de la pieza. El rojo representa una llamada de atención, una llamada de atención hacía nosotros. Es la acción y la aportación de la marca a través del color rojo.

Dado que el tamaño de la letra es mínimo dicha elección cromática no rompe en demasía la lectura de la pieza. Sí es cierto que dicho color mejora enormemente una de las palabras llenas que genera el mayor número de asociaciones con la imagen del anuncio.

Es importante significar que el color blanco del texto es una elección creativa predominante en muchos de las piezas y de los spot de los años 90.

Con respecto al fondo de la pieza encontramos por un lado el color negro predominante. En 3/4 partes de la pieza encontramos un color negro. El color negro se relaciona con lo desconocido, el misterio y el poder (Bivien). Según Lücher, el negro connota distinción y elegancia. El creativo opta por colocar un negro de fondo que por un lado: 
- se asocia con la conducción de noche.

- se asocia con el asfalto y la carretera.

Por otro lado encontramos el fondo luminoso, sobre el que se posa la muestra del pegamento sinuoso por toda la pieza. Un tono luminoso que representa:

- la presencia y el paso del coche por el asfalto.

- la presencia y el paso de la tracción de las cuatro ruedas por el asfalto.

\subsubsection{Ubicación de la imagen en el cuadrante.}

La estructura de la ubicación de la imagen es la siguiente:

Siguiendo las leyes de lectura de imagen de la cultura occidental, la imagen se inicia con el envase del pegamento en la zona inferior izquierda. Posteriormente la mirada se dirige al tapón del envase, y continúa la estela luminosa y de pegamento hasta el final de la estela. Finalmente la mirada se dirige al texto como búsqueda de explicación de la pieza. La mirada finaliza en la última palabra del texto. La única palabra que figura en rojo y en color en toda la pieza. El nombre del modelo del producto.

El itinerario de la mirada seria el siguiente:

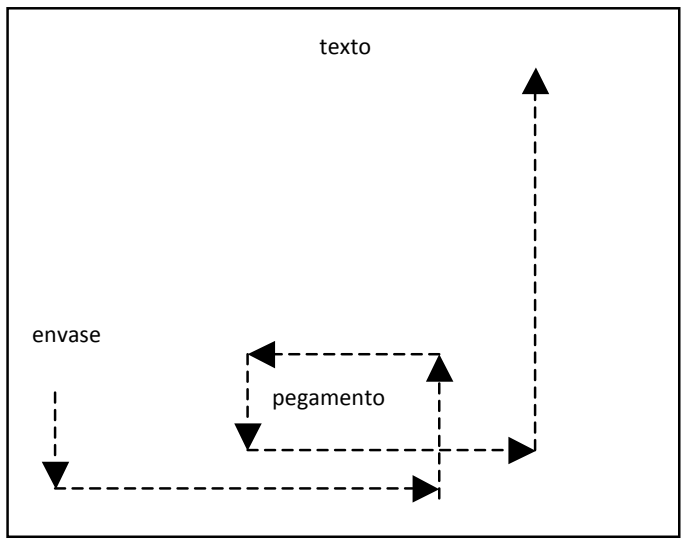

\subsubsection{Dirección.}

La dirección que mantiene la imagen es diagonal. Es la formulación opuesta a la idea de estabilidad y, por ende, es la fuerza más inestable y dinámica, convirtiéndose en la formulación visual más provocadora. Esta dirección puede llevar asociados significados amenazadores y casi subversivos. 


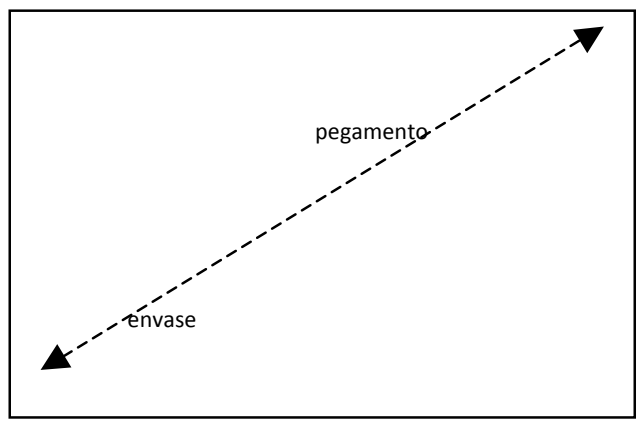

La dirección que mantiene la pieza genera una serie de actividades en el receptor para que se involucre activamente en la pieza.

\subsubsection{Formato de la imagen.}

El ratio es la proporción que existe entre los dos lados de la composición. Desde este punto de vista el ratio de la imagen es corto. El ratio corto es esencialmente descriptivo y es más difícil crear el movimiento. Éste es uno de los factores que influyen en que la pieza no tenga ritmo. La distancia entre el envase y el producto y los límites del formato son inexistentes. Sobre todo en la diagonal principal de la pieza.

\subsection{Análisis de contenido de la pieza gráfica premiada con el sol de oro del Festival Publicitario de San Sebastián de 1997.}

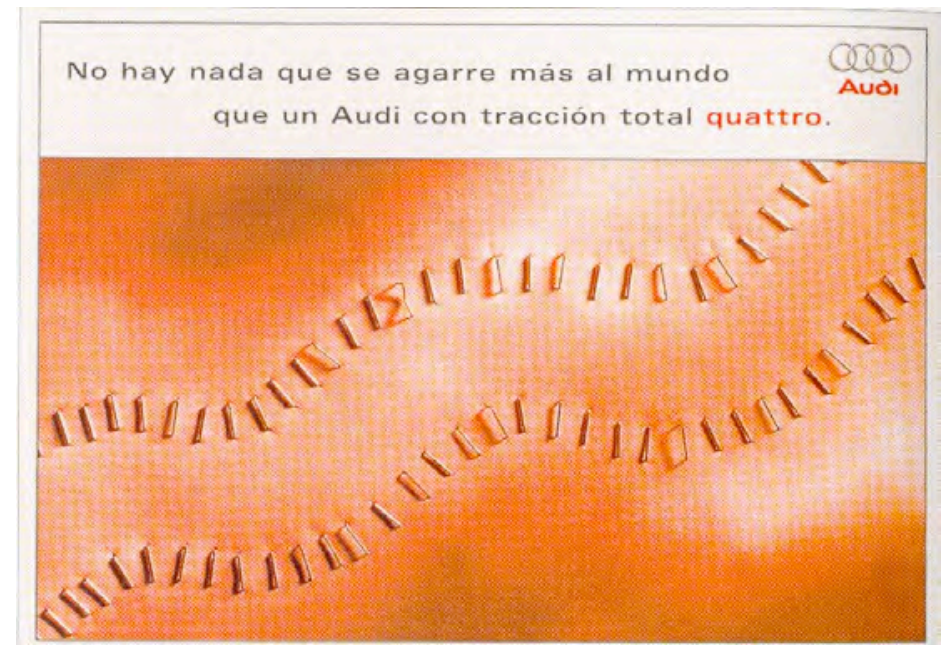

\subsubsection{Contraste de color.}

En esta pieza los colores predominantes son el anaranjado y marrón.

El color anaranjado predomina en el fondo de la pieza, sobre él se enclavan la sucesión de las 63 grapas, distribuidas sinuosamente. 
Según Bivier, el color anaranjado es el color de las cualidades domésticas, expresa seguridad y confort. Es un color que atrae a los indecisos. Es un color que en la pieza está relacionado con el ser humano. Este fondo anaranjado representa claramente la piel o la epidermis humana. Es como si estuviera, el conjunto de las grapas enclavadas en la piel (no determinándose la zona) de un individuo. De esta manera el titular, No hay nada que se agarre más al mundo... obtiene su máximo significado. La metáfora de seguridad del coche, está materializada a través de unas grapas enclavas en la piel. Una forma de demostrar la capacidad del producto de agarrarse al mundo.

Por esta razón el color anaranjado de la piel tiene dos objetivos: uno de representar irónicamente la piel. El segundo el de la seguridad y el confort. Seguridad y confort, difundido por la marca a través de su modelo Quattro.

\subsubsection{Ubicación de la imagen en el cuadrante.}

La estructura de la ubicación de la imagen es la siguiente:

Como ya hemos mencionado anteriormente la pieza ganadora de 1997, mantiene similitudes con la pieza ganadora de 1996 en la susodicha categoría de vehículos y accesorios. Siguiendo las leyes de lectura de imagen de la cultura occidental, la imagen se inicia con la sucesión de las grapas en la zona inferior izquierda de la pieza. Posteriormente la mirada continúa la sucesión ascendente de grapas, hasta finalizar en la zona superior derecha de la pieza. Finalmente la mirada se dirige al texto como búsqueda de explicación de la pieza. La mirada finaliza en la última palabra del texto.

La única palabra que figura en rojo y en color en toda la pieza. El nombre del modelo del producto. Podemos comprobar la enorme similitud en este apartado en relación a la pieza ganadora de $1997 .^{2}$

El itinerario de la mirada seria el siguiente:

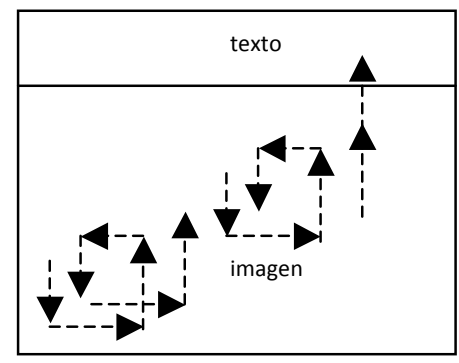

\subsubsection{Dirección.}

La dirección que mantiene la imagen es diagonal. Es la formulación opuesta a la idea de estabilidad y, por ende, es la fuerza más inestable y dinámica, convirtiéndose en la 
formulación visual más provocadora. Esta dirección puede llevar asociados significados amenazadores y casi subversivos.

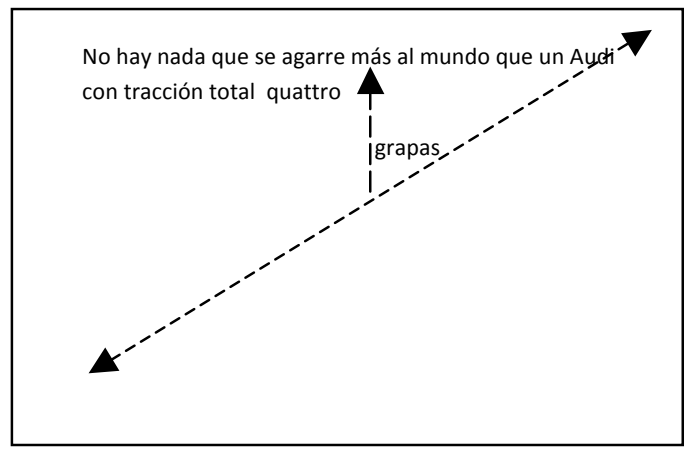

La dirección que mantiene la pieza genera una serie de actividades en el receptor para que se involucre activamente en la pieza.

\subsubsection{Formato de la imagen.}

El ratio es la proporción que existe entre los dos lados de la composición. Desde este punto de vista el ratio de la imagen es corto. El ratio corto es esencialmente descriptivo y es más difícil crear el movimiento. Éste es uno de los factores que influyen en que la pieza no tenga ritmo. La distancia entre el envase y el producto y los límites del formato son inexistentes. Sobre todo en la diagonal principal de la pieza.

\subsection{Análisis de contenido de la pieza gráfica premiada con el sol de oro del Festival Publicitario de San Sebastián de 1998.}

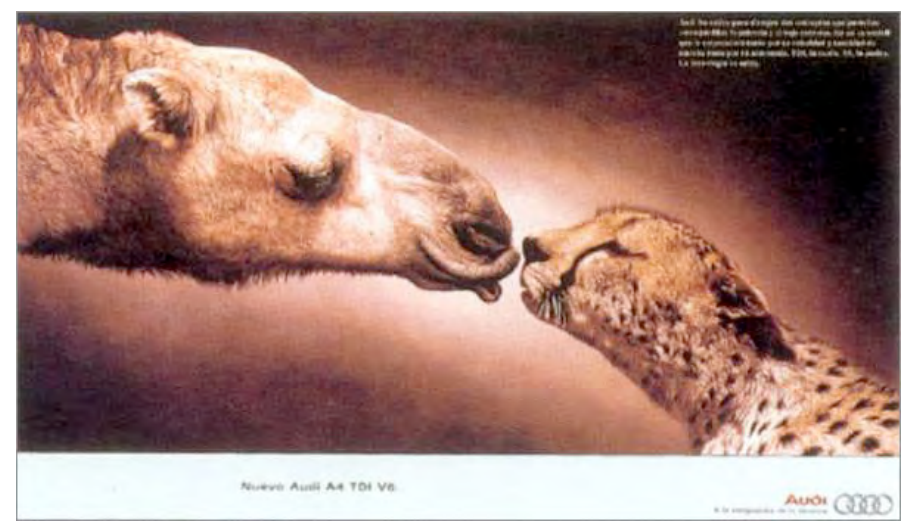

\subsubsection{Contrate de color}

Marrón: es el tono predominante de la pieza. El marrón es el color del campo, de la madre tierra de la templanza y de la tranquilidad ${ }^{3}$. Todas las características semánticas que el producto necesita se consolidan a través de color marrón. Ese amor tranquilo, reposado y maduro que mantiene el camello y el guepardo. Es un color de la

\footnotetext{
${ }^{3}$ Lüscher, Max, Test de los colores, texto adaptado por Ian A. Scout, Ediciones Paidos, Barcelona 1993. Página 61.
} 
naturaleza madura y austera. Esa naturaleza sabía que es capaz de unir a dos conceptos, o dos animales absolutamente distantes.

Negro: Se relaciona con lo desconocido, el misterio y el poder ${ }^{4}$. Según Lüscher, el negro connota distinción, elegancia y cuando se combina con el oro posee el encanto del lujo y la fascinación. Las sensaciones positivas asociadas a este color son la de seriedad, de nobleza y de pensar. Encontramos en la pieza muchos espacios negros y oscuros, tanto en la figura de los animales, como en el fondo. El lujo la elegancia y la distinción son tres factores que el anunciante quiere asociar al AUDI A4. Por lo tanto la utilización del color negro coincide exactamente con el objetivo de la agencia. La magia sobre la que aparece el camello y el guepardo tiñe de un misterio y sofisticación que sólo se puede alcanzar con este color. En la pieza para televisión, el color negro obtenía mayor protagonismo aún, dado que en los primeros segundos de la pieza la imagen es casi absolutamente negra.

Con respecto al color del cuerpo de texto es importante significar que el color blanco del texto es una elección creativa predominante en muchos de las piezas y de los spot de los años 90 . No pretende llamar la atención. Es un texto secundario pero no es esencial para el entendimiento de la pieza.

Hay unas piezas blancas en la parte superior e inferior del anuncio, con el objetivo de permitir una mayor facilidad de lectura sobre el texto (titulares). El texto de los titulares tiene una mayor importancia que el del cuerpo de texto. Es mucho más importante para el entendimiento del sentido de la pieza. Por esta razón han optado por posar el texto negro sobre las piezas blancas. De esta manera el texto no pasa tan desapercibido como el del cuerpo de texto.

\subsubsection{Ubicación de la imagen en el cuadrante.}

La estructura de la ubicación de la imagen es la siguiente:

Siguiendo las leyes de lectura de imagen de la cultura occidental, la lectura de la imagen se inicia en el centro neurálgico o en el área de condensación semántica de la pieza. Ésta se localiza claramente en el centro de la pieza; en el lugar donde los labios de ambos animales de encuentran para sellar un beso para siempre.

El segundo, y obligado paso en la lectura del anuncio son los titulares I y II, en la parte superior izquierda y derecha de la pieza.

La tercera y última estación en el viaje de la lectura de la pieza, es la zona inferior derecha e izquierda de la pieza. En la zona izquierda sabremos el modelo del vehículo. En la zona inferior derecha conoceremos la marca que respalda el producto y su filosofía gerencial o eslogan genérico:

\footnotetext{
${ }^{4}$ Clemente, Miguel y Santalla, Zuleyma. El Documento Persuasivo. Universidad Complutense de Madrid. Ediciones Deusto S.A. Bilbao 1991. Página 130.
} 
AUDI, A la vanguardia de la técnica.

El itinerario de la mirada seria el siguiente:

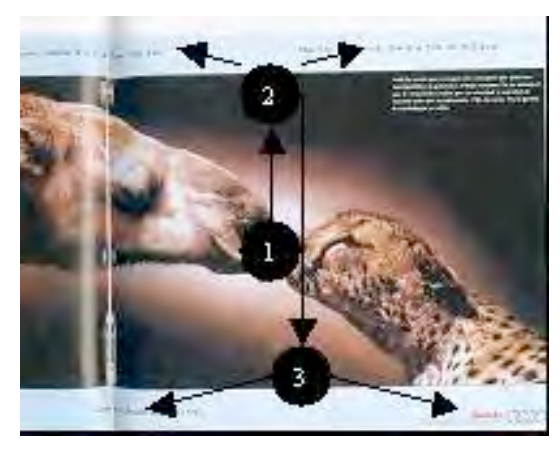

\subsubsection{Dirección.}

La dirección que mantiene la imagen es vertical-horizontal. La relación básica del ser humano con su entorno es la relación horizontal-vertical. El individuo, cuando percibe, siempre tiende a estabilizar lo percibido imponiéndole un eje vertical con su referente secundario horizontal. Esta dirección genera equilibrio y estabilidad. Este es justo el objetivo que busca el emisor. Pretende que el receptor en esa búsqueda del equilibrio simétrico de la pieza, se pose sólidamente sobre el centro de los labios de ambos animales:

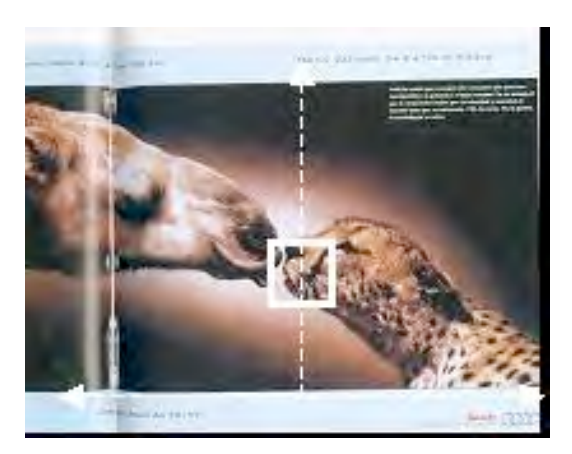

La calma de la unión emocional entre el camello y el guepardo se consigue materializar con una dirección recta que ayuda a generar un mensaje sutil y poco provocador. Un mensaje templado y reposado.

La tensión viene dada por lo inesperado, lo irregular, lo complejo y lo inestable. Por el contrario la regularidad y el equilibrio traen como consecuencia directa el reposo. ${ }^{5}$

\subsubsection{Formato de la imagen.}

El ratio es la proporción que existe entre los dos lados de la composición. Desde este punto de vista el ratio de la imagen es muy corto. El ratio corto es esencialmente

\footnotetext{
${ }^{5}$ Clemente, Miguel y Santalla, Zuleyma. El Documento Persuasivo. Universidad Complutense de Madrid. Ediciones Deusto S.A. Bilbao 1991. Página 112.
} 
descriptivo y es más difícil crear el movimiento. Éste es uno de los factores que influyen en que la pieza no tenga ritmo. Más cadencia que ritmo. Los límites del formato son inexistentes.

\subsection{Análisis de contenido de la pieza gráfica premiada con el sol de oro del Festival Publicitario de San Sebastián de 1999.}

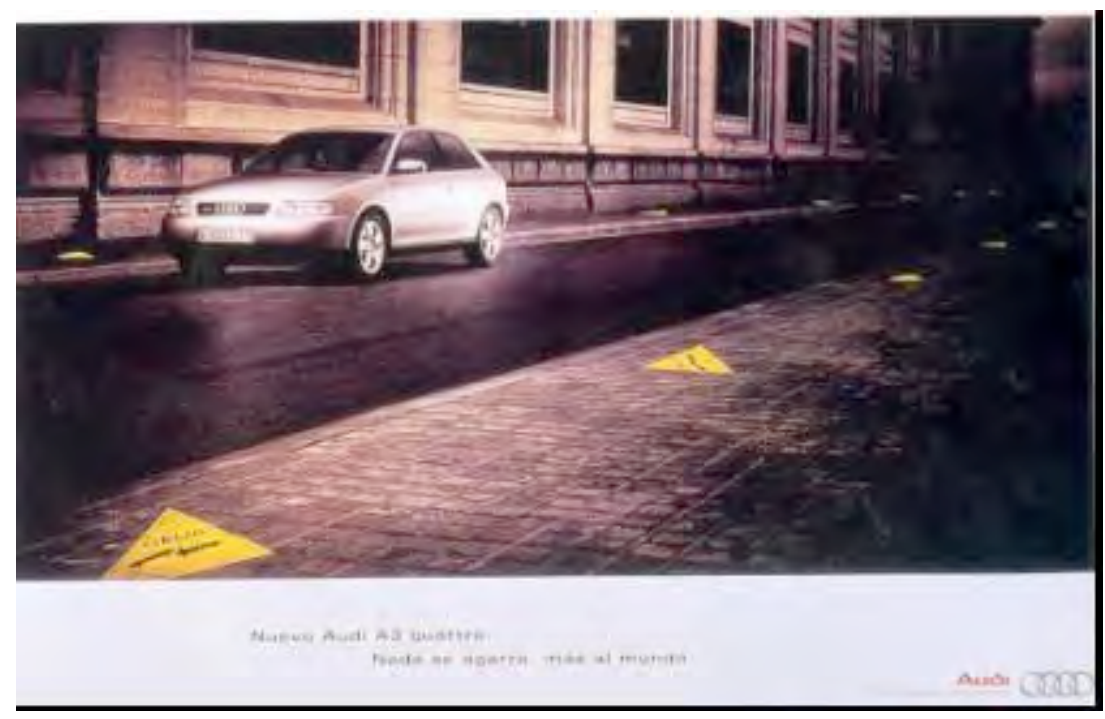

\subsubsection{Contraste de color.}

Esta pieza tiene claramente dos colores predominantes. Por un lado los tonos oscuros, negros y grises, que predominan un $85 \%$ de la imagen. Por otro los colores amarillo de las pegatinas para el aviso de grúa, que pueden llegar a ocupar un escaso 15\%.

Significado de los tonos oscuros: negros, grises y plateados de la calle y el coche:

El negro se relaciona con lo desconocido, el misterio y el poder. Según Lüscher, el negro connota distinción, elegancia. También es el color de la tristeza y puede expresar todo lo que está escondido y prohibido. La imagen de nuestra pieza connota todo este conjunto de factores. Es una calle triste, una calle sobre la que se supone que ha habido mucha actividad anteriormente (horas atrás), pero que ya ha sucedido todo. El misterio y la incógnita cubren todos sus contornos. De hecho es tanta la oscuridad y la seriedad de la foto que en la zona derecha de la imagen (fondo de la calle), caso no se diferencia el resto de la acera y de la fachada del supuesto teatro.

La sensación de seriedad, nobleza y de personalidad están posadas sobre la pieza.

El color plateado del coche es por una parte un color señorial que va muy en la línea con el entorno en el que se está proyectando el producto. Por otro lado la agencia se ve obligada a utilizar un color de estas características, para continuar con el ambiente oscuro y misterioso de la pieza. 
Amarillo de la pegatina de la grúa.

Concretamente 13 pegatinas amarillas ( 7 en la acera de la derecha y 6 en la acera de la izquierda) alinean perpendicularmente las aceras, avisando de la llegada obligatoria de la grúa en el caso de dejar estacionado el coche en dicha zona. El amarillo significa inconstancia, y sobre todo connota precaución. Es una señal un icono conocido por todos y que todos identificamos rápidamente en el ámbito del tráfico. Es un color que está frivolizando con la situación. Un color gracias al producto, puede permitir reírse de la indicación o más bien de la amenaza imperativa. Una amenaza que ha sido cumplida sin contemplación con todos lo coches de la calle. La sobreestimulación del amarillo es un color luminoso e imaginativo que logra el equilibrio real e interpretativo para la pieza.

\subsubsection{Ubicación de la imagen en el cuadrante.}

La lectura de la imagen sería la siguiente:

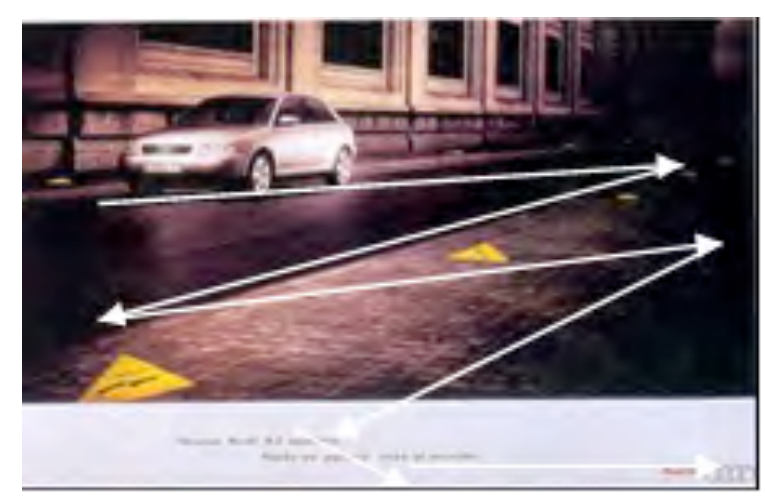

La lectura de la imagen comienza en el coche posicionado en la acera de la fachada del supuesto teatro. A partir de ahí la mirada se dirige hacía la derecha hasta el final de la calle. Finalmente la mirada vuelve a la acera; a las pegatinas que avisan de la llegada de la grúa si se aparca cualquier vehículo.

A partir de ahí la mirada se dirige hacía el texto.

\subsubsection{La dirección.}

La dirección que mantiene la imagen es claramente diagonal. Es la formulación opuesta a la idea de estabilidad y, por ende, es la fuerza más inestable y dinámica, convirtiéndose en la formulación visual más provocadora. Esta dirección puede llevar asociados significados amenazadores y casi subversivos. 


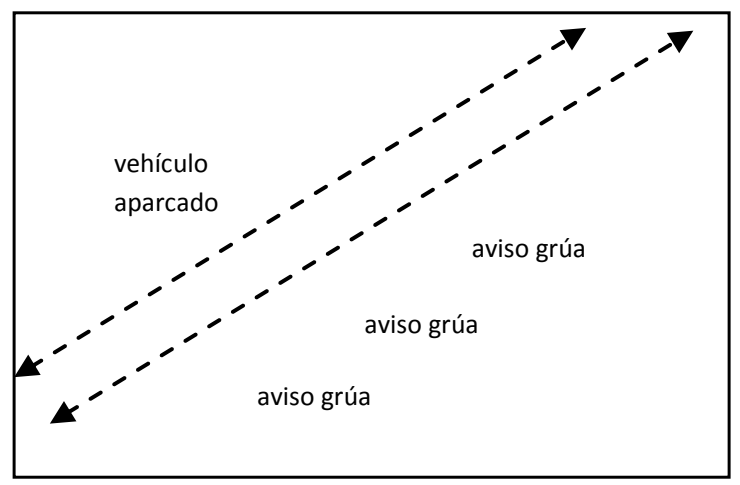

Una imagen con una dirección y una tensión claramente dinámica. Una disposición dinámica desde una perspectiva de la dirección, pero una imagen que por contenido, ritmo y elementos es de frialdad. La dirección ayuda dinamizar la imagen.

\subsubsection{Formato de la imagen.}

Con respecto al ratio de nuestra pieza analizada y ganadora del Festival Publicitario de 1999, podemos afirmar que tiene ratio largo. El ratio largo es fundamentalmente narrativo y es más fácil crear direcciones, ritmos y sensación de movimiento.

\subsection{Análisis de contenido de la pieza gráfica premiada con el sol de oro del Festival Publicitario de San Sebastián de 2000.}

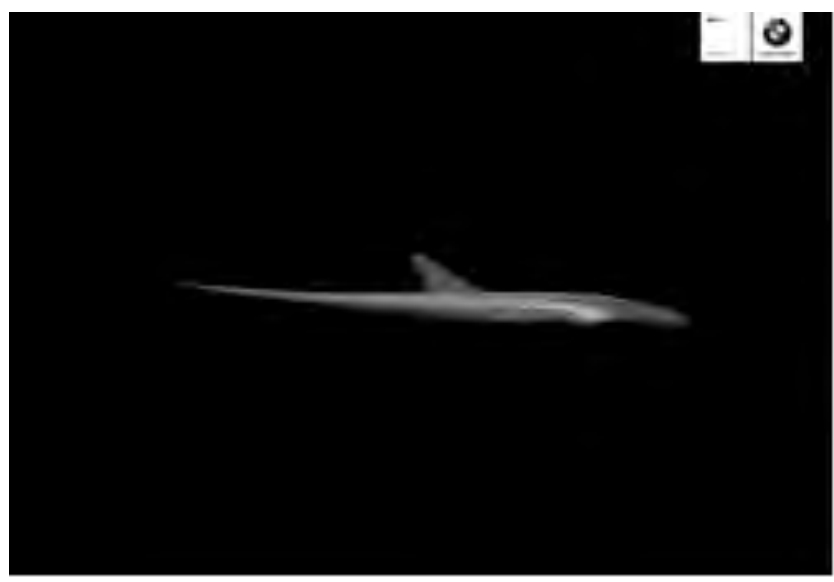

\subsubsection{Contrate de color.}

- Negro: Es el color de una moda sofisticada para ambos sexos. Se relaciona con lo desconocido, el misterio y el poder. Según Lüscher, el negro connota distinción, elegancia. El negro es el color de la tristeza y puede expresar todo lo que está escondido y prohibido. ${ }^{6}$ Es un color que en este caso genera incógnita y elementos

\footnotetext{
${ }^{6}$ Clemente, Miguel y Santalla, Zuleyma: Op. cit., página 130.
} 
escondido. Todo lo que es una incógnita y escondido el receptor tiende a buscar información que la complete. El negro es el color claramente predominante en la pieza. El color negro ocupa aproximadamente el $90 \%$ de la pieza. Tanto del fondo (80\%) como de la imagen del tiburón (10\%), es el negro en diferentes tonalidades el que logra bañar de forma casi monopolizante la pieza. El negro es el color del tiburón dentro del mar. Y en las más altas profundidades del mar es el negro el color principal. Para hacer la analogía entre el tiburón y el descapotable es el color negro el que mejor favorece la fusión entre ambas imágenes. Es una pieza muy relajada visualmente dado que la proporción del espacio con respecto al fondo es mínima.

- Blanco: Es un color utilizado de fondo para que el texto se pueda resaltar sobre el fondo negro. Son exactamente dos piezas blancas, colocadas en la zona superior derecha del anuncio. El blanco en esta ocasión tiene dos funciones:

- Consigue servir de fondo al texto del anuncio:

-BMW Z3. ¿Te gusta conducir?.

- Consigue mantener la estructura estética del negro dentro de la pieza. El blanco es el color ideal para conseguir mantener la tendencia monopolística del negro en la pieza.

- Azul: Es un color generador de sensación de infinidad, inspira confianza y puede asociarse con lo espiritual. Este es uno de los principales factores sobre los que se está posando la filosofía conceptual de la marca, en las últimas fechas. Dada la escasa presencia del color azul dentro de la pieza, simplemente decir se encuentra en el logotipo de la marca. Además es un color que ayuda y potencia la predominancia cromática de la pieza. Colores negros, azules y blancos. Son todos tonos que generan incógnita y que son fríos.

\subsubsection{Ubicación de la imagen en el cuadrante.}

La estructura de la ubicación de la imagen es la siguiente:

La lectura de la pieza se inicia con la imagen, y su recorrido (de izquierda a derecha) y continúa y finaliza en el texto. Dentro del texto la lectura es de la pieza izquierda, en primer lugar, y luego a la pieza derecha.

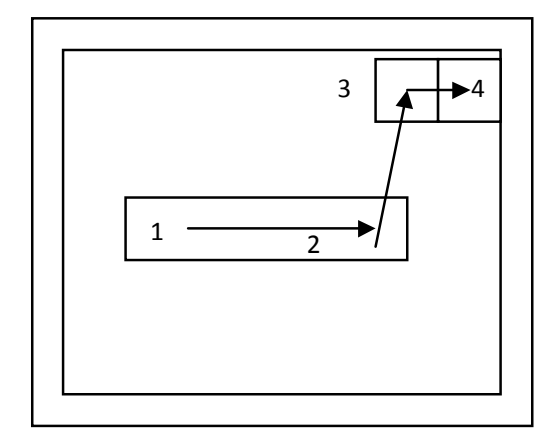




\subsubsection{Dirección.}

La pieza mantiene una dirección claramente horizontal-vertical. La dirección horizontalvertical genera estabilidad y escasez de dinamismo. La intención primordial de la pieza no es provocar a través de la estructura. Genera quietud, calma y estabilidad. Todo esto unido con la simplicidad de la imagen, hace aumentar aún más la estabilidad de la pieza.

\subsubsection{Formato de la imagen.}

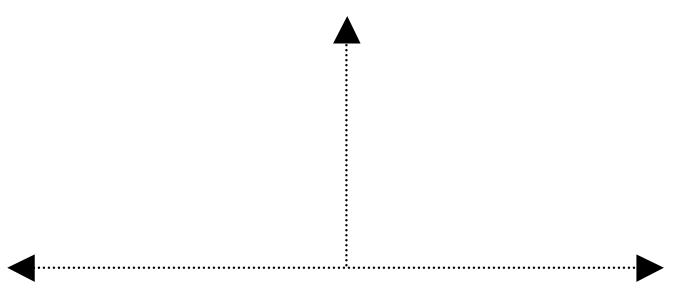

El ratio es la proporción que existe entre los dos lados de la composición. Desde este punto de vista el ratio de la imagen es corto. La pieza no pretende generar movimiento y si aumentar estéticamente la imagen y la relajación visual.

\subsection{Análisis de contenido de la pieza gráfica premiada con el sol de oro del} Festival Publicitario de San Sebastián de 2001.

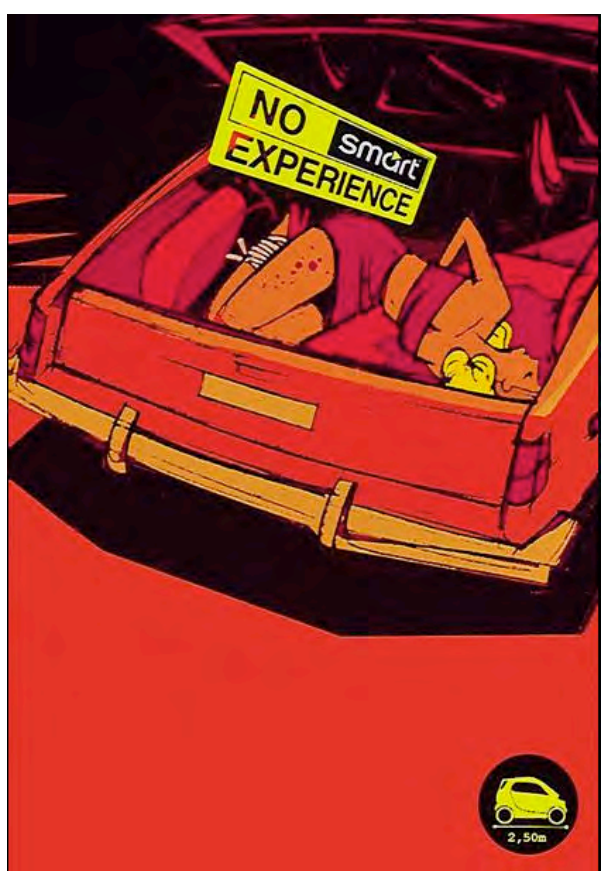




\subsubsection{Contrate de color.}

- Rojo: Existe en toda la pieza un color que predomina claramente en toda la superficie: el color rojo. El color rojo genera una serie de significados siempre relacionados con la actividad. Es un color que se acerca y nos invade hasta el punto de activar nuestra atención. Es un color que se asocia con alegría, pasión, emoción, libertad... Es la apuesta del receptor por este tipo de producto. El color rojo es el idóneo para narrar una situación alarmante y de peligro. Toda la pieza está teñida por el dibujo como herramienta de comunicación plástica; y el rojo es el protagonista que permite la comunicación de una situación tensa de narración. El color rojo invade gran parte de la superficie del fondo de la pieza. Además tanto el vehículo como la chica tienen una clara presencia del color rojo. Una tensión materializada en rojo presente en un $75 \%$ de la pieza.

- Amarillo: El segundo color, en orden de predominancia, dentro de la pieza es el color amarillo. El color amarillo representa inconstancia, y sobre todo connota precaución. Una precaución que unida a la indiscutible presencia del rojo se acentúa mucho más. Es un color que genera imaginación. Dado que el amarillo es el color que representa a la presencia de la marca dentro de la pieza; la imaginación está asegurada. El color amarillo está presente en la representación visual del perfil del coche, dibujado en la zona inferior derecha de la pieza.

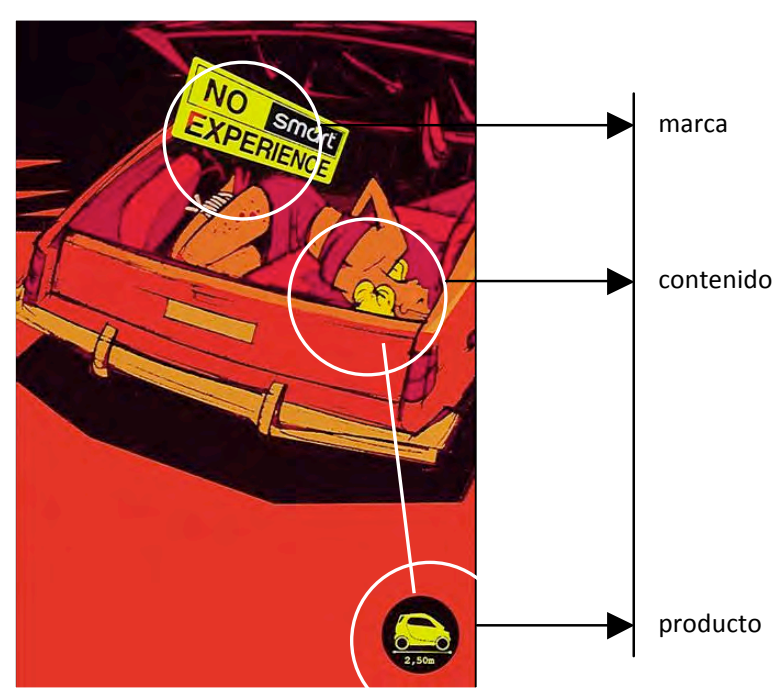

La presencia del amarillo, esta orientada a representar tres elementos semánticos. Por un lado la marca de la empresa que publicita el producto. La marca es SMART. A través del icono, amarillo, introducido en su nombre podemos captar el toque personal de la marca. En segundo lugar encontramos un luminoso color amarillo en el pelo de la chica, amordaza en el interior del maletero del vehículo. Generando la tensión de una experiencia que no se puede dar con nuestro coche, dado que no tiene maletero. El amarrillo permite un foco de atención. El tercer elemento de presencia del color está en la representación del modelo, en la zona inferior derecha de la pieza. Una 
representación vital por le contenido para el entendimiento de la pieza, y visualmente equilibra el resto de la pieza.

- Negro: El último color con suficiente presencia en la pieza para lograr significado es el color negro. Es un color que se relaciona con lo desconocido, el misterio y el poder. Según Lüscher, el negro connota distinción, elegancia. El negro es el color de la tristeza y puede expresar todo lo que está escondido y prohibido.7 La presencia de ese desconocimiento se produce en la zona superior de la pieza y en la sombra de los bajos del vehículo. Ese misterio del color alcanza su máximo significado en la zona superior del vehículo. Es una zona en la que se puede ocultar alguna huella o autor causante del aprisionamiento de la chica. Se utiliza como fondo en el nombre de la marca y en la presencia de la imagen del vehículo en la zona inferior derecha de la pieza. Y se utiliza como figura en el único titular de la pieza: NO EXPERIENCE.

- Blanco: Analizamos y comentamos anecdóticamente la presencia del blanco porque entendemos que tiene una obligada presencia en la marca del producto a publicitar. El color blanco de la letra, muy utilizado en los últimos tiempos, permite localizar y resaltar claramente el nombre de la marca sin otro objetivo de captación, aunque se localice en una zona de clara condensación semántica.

\subsubsection{Ubicación de la imagen en el cuadrante.}

La estructura de la ubicación de la imagen es la siguiente:

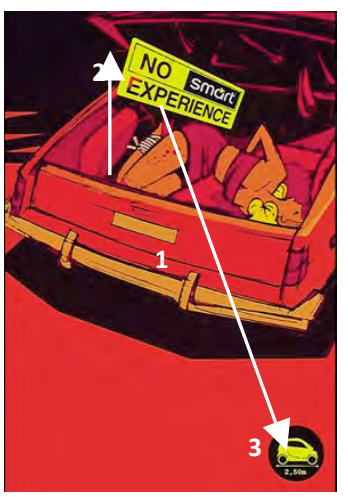

La lectura de la pieza en el cuadrante se inicia en la zona donde se agrupan el mayor número de elementos de significados: el maletero del vehículo. A partir de ese instante de captación, las pupilas del receptor se dirigen hacia la zona superior del maletero donde se ubica el nombre de la empresa y el único titular: NO EXPERIENCE SMART. El final de la lectura se produce cuando el receptor, habiendo obtenido un $75 \%$ del significado de la pieza, encuentra el final del significado publicitario; cuando capta el dibujo del coche y la medida de su longitud: $2,5 \mathrm{~m}$. Es en la zona inferior derecha de la pieza cuando el receptor obtiene el final de su itinerario visual.

\footnotetext{
${ }^{7}$ Clemente, Miguel y Santalla, Zuleyma: Op. cit., página 130.
} 


\section{Dirección.}

La dirección que mantiene la imagen es claramente diagonal. Es la formulación opuesta a la idea de estabilidad y, por ende, es la fuerza más inestable y dinámica, convirtiéndose en la formulación visual más provocadora. Esta dirección puede llevar asociados significados amenazadores y casi subversivos.

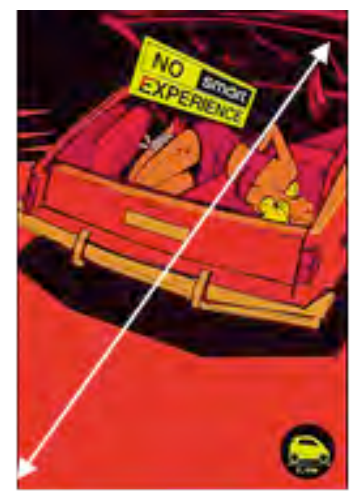

\subsubsection{Formato de la imagen.}

El ratio es la proporción que existe entre los dos lados de la composición. Desde este punto de vista el ratio de la imagen es muy corto. El ratio corto es esencialmente descriptivo y es más difícil crear el movimiento. Los límites del formato son inexistentes. Pero a pesar del ratio existen otros muchos elementos que permiten elevar el ritmo de la misma: color, textura....

\subsection{Análisis de contenido de la pieza gráfica premiada con el sol de oro del Festival Publicitario de San Sebastián de 2002.}

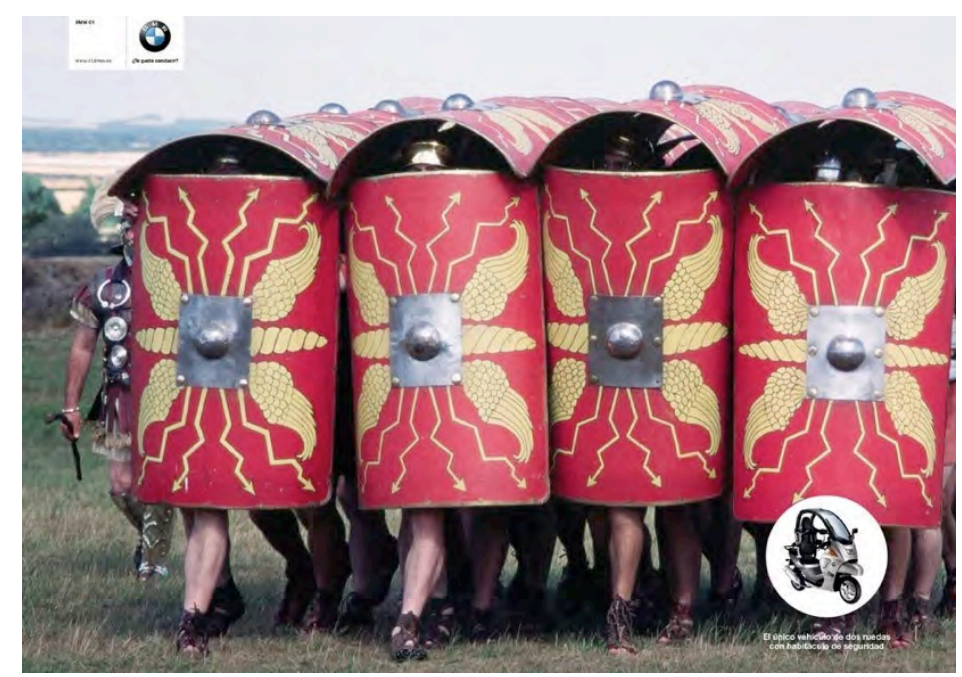




\subsubsection{Contrate de color.}

- Rojo: Existe en toda la pieza un color que predomina claramente en toda la superficie: el color rojo. Este color viene por el alto porcentaje de color que mantienen los fondos de los ocho escudos que aparecen El color rojo genera una serie de significados siempre relacionados con la actividad. Es un color que se acerca y nos invade hasta el punto de activar nuestra atención. Es un color que se asocia con alegría, pasión, emoción, libertad... El color rojo es el idóneo para narrar una situación alarmante y de peligro. La imagen de la centuria narra a través del color rojo el peligro y alarma de un grupo de estas características.

- Marrón: El marrón es el color del campo, de la madre tierra de la templanza y de la tranquilidad ${ }^{8}$. Todas las características semánticas del color marrón se cumplen en las zapatillas o sandalias de los romanos en su paso firme por el campo.

- Verde: Es el color de la naturalidad y de los espacios externos. En este caso el césped del campo implica naturaleza. La naturaleza está enfocada como el entorno de la lucha y esa lucha es una clara metáfora de la lucha en la ciudad.

\subsubsection{Ubicación de la imagen en el cuadrante.}

La estructura de la ubicación de la imagen es la siguiente:

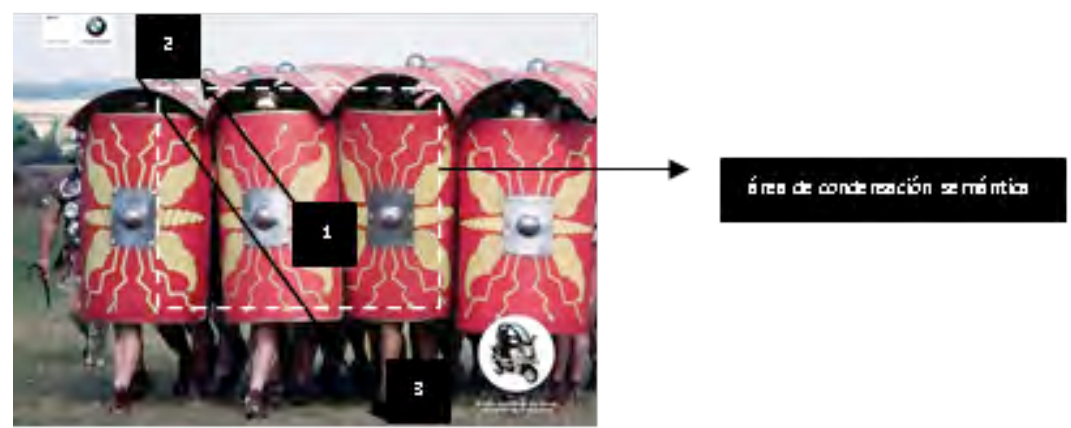

La lectura de la pieza en el cuadrantf se inicia en la zona céntrica, en la zona de condensación semántica de la pieza ( $p$ unto 1). El itinerario de la mirada pasa como segunda estación a la zona superior izçuierda de la pieza, donde está la marca de la empresa (punto 2). La tercera estación pasa por la muestra del producto y el titular principal de la pieza (punto 3).

\footnotetext{
${ }^{8}$ Lüscher, Max, Test de los colores, texto adaptado por Ian A. Scout, Ediciones Paidos, Barcelona 1993. Página 61.
} 


\subsubsection{Dirección.}

La dirección que mantiene la imagen es claramente diagonal. Es la formulación opuesta a la idea de estabilidad $\mathrm{y}$, por ende, es la fuerza más inestable y dinámica, convirtiéndose en la formulación visual más provocadora. Esta dirección puede llevar asociados significados amenazadores y casi subversivos. Es importante reseñar que a priori, por la presentación horizontal de las cuatro filas de romanos, puede parecer que la dirección y la tensión de la pieza sean horizontal. Pero debido a la oblicuidad con la marcha la centuria, y la orientación de la fotografía, la dirección es claramente diagonal.

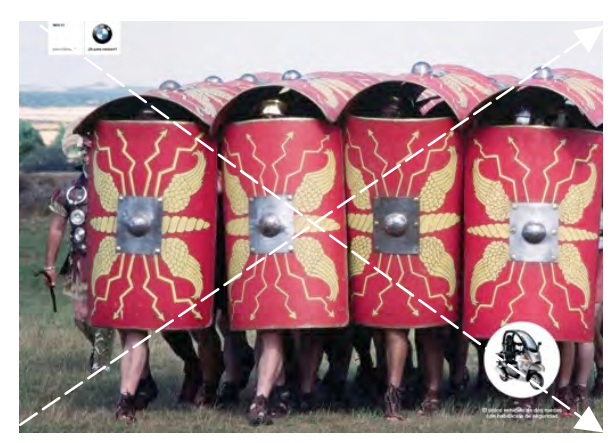

\subsubsection{Formato de la imagen.}

El ratio es la proporción que existe entre los dos lados de la composición. Desde este punto de vista el ratio de la imagen es muy corto. El ratio corto es esencialmente descriptivo y es más difícil crear el movimiento. Los límites del formato son inexistentes. Pero a pesar del ratio existen otros muchos elementos que permiten elevar el ritmo de la misma: color, textura, dirección oblicua... 


\subsection{Análisis de contenido de la pieza gráfica premiada con el sol de oro del Festival Publicitario de San Sebastián de 2003.}

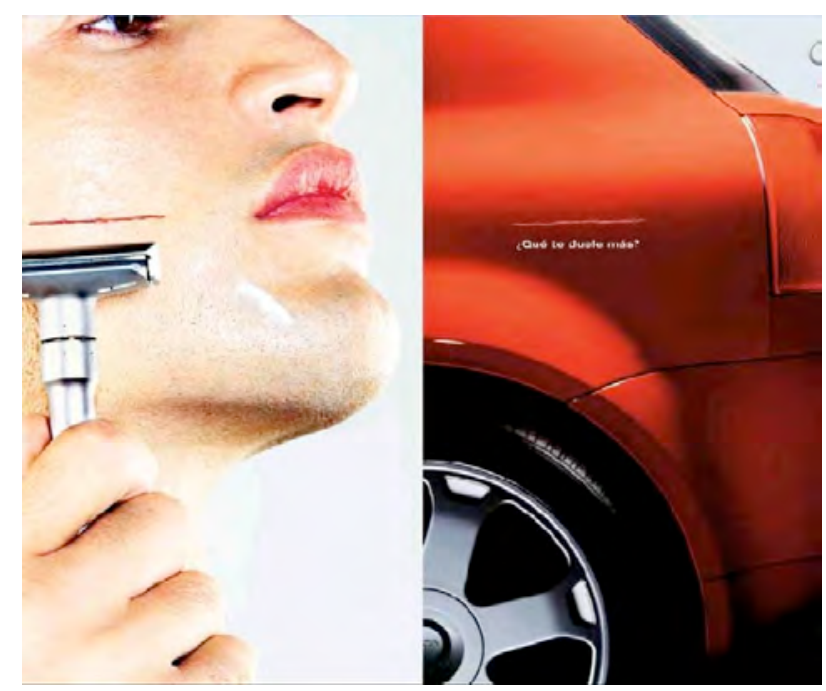

\subsubsection{Contrate de color.}

- Rojo: Existe en un porcentaje importante de la pieza, una clara predominancia del color rojo. Se puede apreciar con una predominancia muy alta (determinar el porcentaje) en la fotografía de la derecha. En la izquierda lo podemos localizar en el color de los labios del modelo, y en el corte en el rostro del modelo. El color rojo genera una serie de significados siempre relacionados con la actividad. Es un color que se acerca y nos invade hasta el punto de activar nuestra atención. Es un color que se asocia con alegría, pasión, emoción, libertad... El color rojo es el idóneo para narrar una situación alarmante y de peligro. En este caso es un color ideal para narrar la emoción perceptiva de la pieza. El color psicológico de la pieza es el rojo. Un color que te permite interpretar la realidad a través de la emoción.

- Negro: Es un color que se relaciona con lo desconocido, el misterio y el poder. Según Lüscher ${ }^{9}$, el negro connota distinción, elegancia. En este caso la testimonial presencia del color negro es obligada debido a los neumáticos del vehículo. Es una identidad cotidiana de los vehículos, por lo tanto no podemos llegar a interpretar más que la obligada presencia de los neumáticos en un vehículo.

\footnotetext{
${ }^{9}$ Lüscher, Max, Test de los colores, texto adaptado por Ian A. Scout, Barcelona 1993, Ediciones Paidos, página 62
} 


\subsubsection{Ubicación de la imagen en el cuadrante.}

La estructura de la ubicación de la imagen es la siguiente:

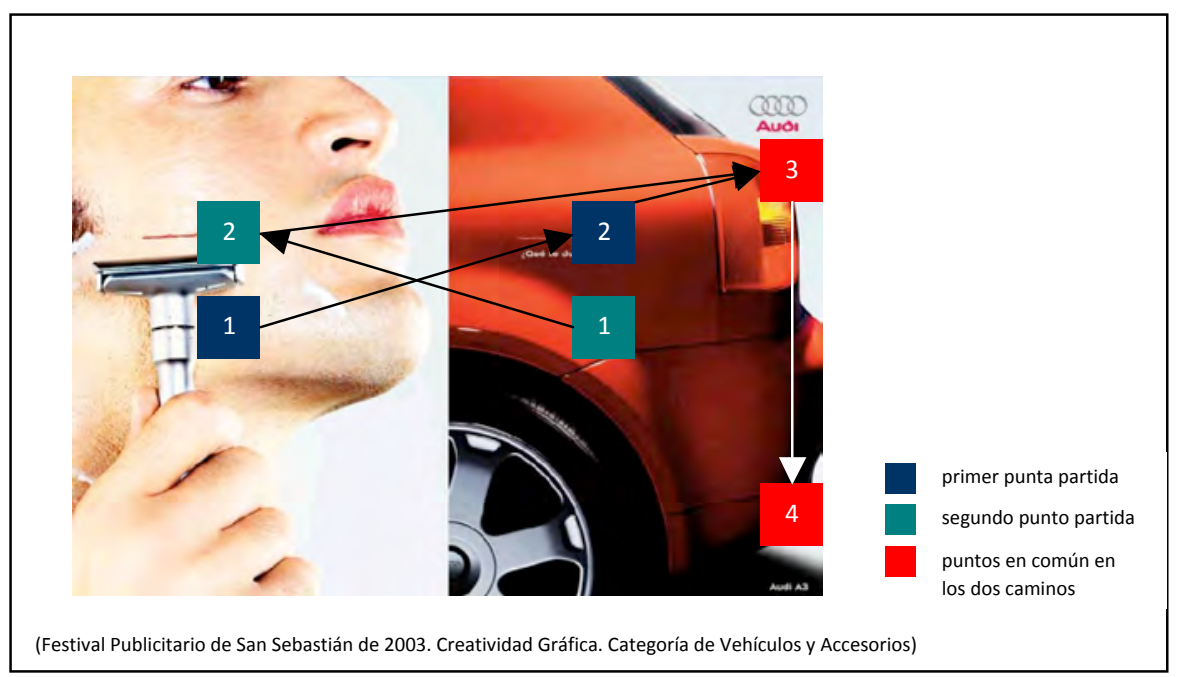

- Lectura 1. Comienza la lectura en la zona izquierda de la pieza. (elementos color azul) Concretamente en la zona del corte en el rostro causado por la maquinilla, en el primerísimo primer plano de la fotografía del modelo. La lectura continúa en la zona derecha (trayectoria convencional) situado en el desperfecto del lateral izquierdo del vcehículo. Posteriormente la mirada se dirige a la zona superior donde está la marca publicitada y finalmente a la zona inferior derecha de la pieza donde aparece el modelo de la marca (Audi A3) (punto 3 y punto 4, puntos comunes).

- Lectura 2. El punto de inicio de la segunda lectura posible está posicionado en el desperfecto del vehículo (elemento color verde). A partir de ahí la dirección de la mirada se posa en el corte en la cara de la zona izquierda de la pieza (dirección no convencional; derecha-izquierda). Posteriormente la dirección de la mirada cruza la piza y finaliza de la misma forma que en la anterior posibilidad (punto 3 y punto 4 , puntos comunes).

La consecuencia de la multilectura es una gran participación por parte del receptor y por supuesto, sobre todo en la segunda lectura una gran tensión visual. Sobre todo en esta segunda lectura los porcentajes de atención se ven claramente aumentados.

\subsubsection{Dirección.}

La dirección que mantiene la imagen es claramente vertical-horizontal. Desde el punto de vista de la dirección y la tensión, la pieza es claramente estable. Los elementos visuales que fluyen sobre la pieza están claramente orientados vertical u horizontalmente. De esta manera la pieza es mucho más estable y dinámica. El resultado final ante el receptor es claramente sereno y poco provocador. De hecho la 
disposición de la pieza, esta formalizada y dividida a través de dos fotografías. Una línea real divide equidistantemente las dos secuencias del anuncio: El rostro del modelo y la popa del vehículo publicitado. Esta división ayuda considerablemente a que el resultado final sea claramente estable: Vertical-horizontal.

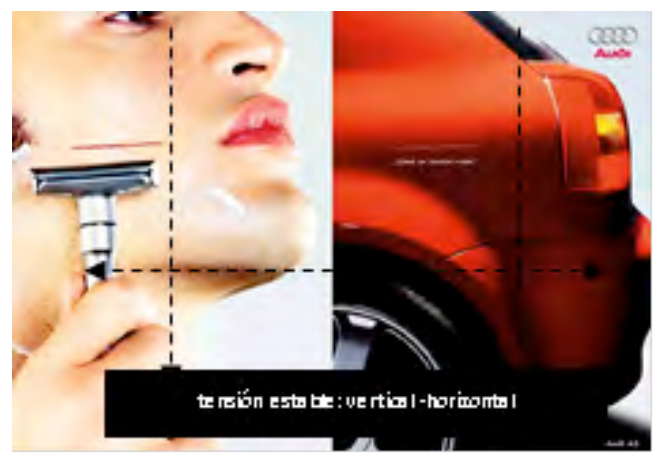

\subsubsection{Formato de la imagen.}

El ratio es la proporción que existe entre los dos lados de la composición. Desde este punto de vista el ratio de la imagen es inexistente. El ratio corto o nulo es esencialmente descriptivo y es más difícil crear el movimiento. Los límites del formato son inexistentes.

\section{CONCLUSIONES}

La marca que más soles de oro ha recibido en el Festival Publicitario de San Sebastián desde 1993 hasta 2003 en la categoría de vehículos y accesorios, es Audi con 45,45\%. En segundo lugar Volkswagen; 27,27\%, BWM 18,18\% y Mercedes 9,09\%.

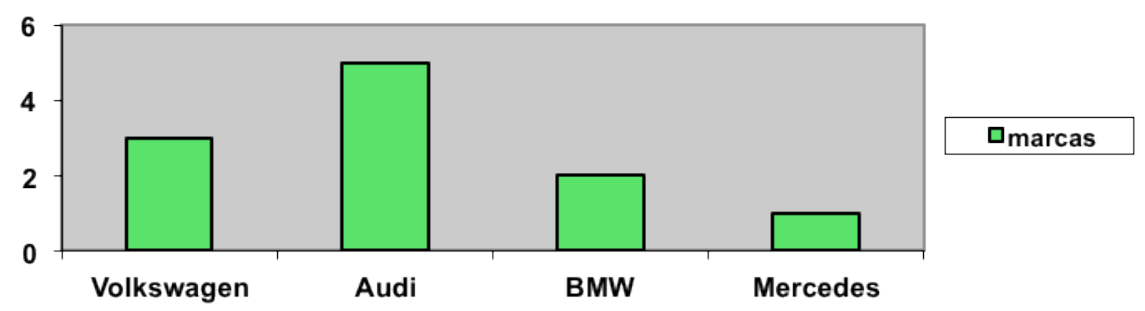

En función del color predominante en los años investigados podemos concluir que el rojo es el color más utilizado; $45,45 \%$ en las piezas ganadoras en el Festival de San Sebastián de la categoría de vehículos y accesorios. En segundo lugar los colores más utilizados son el gris $18,18 \%$ y el naranja $18,18 \%$. 

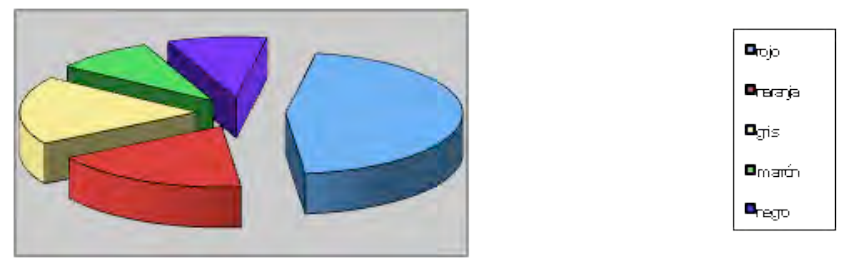

Con respecto a la ubicación de la imagen dentro de las piezas ganadoras del Festival de Publicidad de San Sebastián podemos afirmar que la zona más utilizada para la colocación de la imagen es a parte céntrica del formato. La media de ubicación de la imagen es 2,95. A medida que avanzan los años, las piezas tienden a ubicar la imagen en los primeros cuadrantes (1,2 y $3^{\circ}$ cuadrante. Media: 2,75 en los últimos 6 años (1998-2003). En cambio en los primeros 5 años (1993-1997), la media es de 3,2.
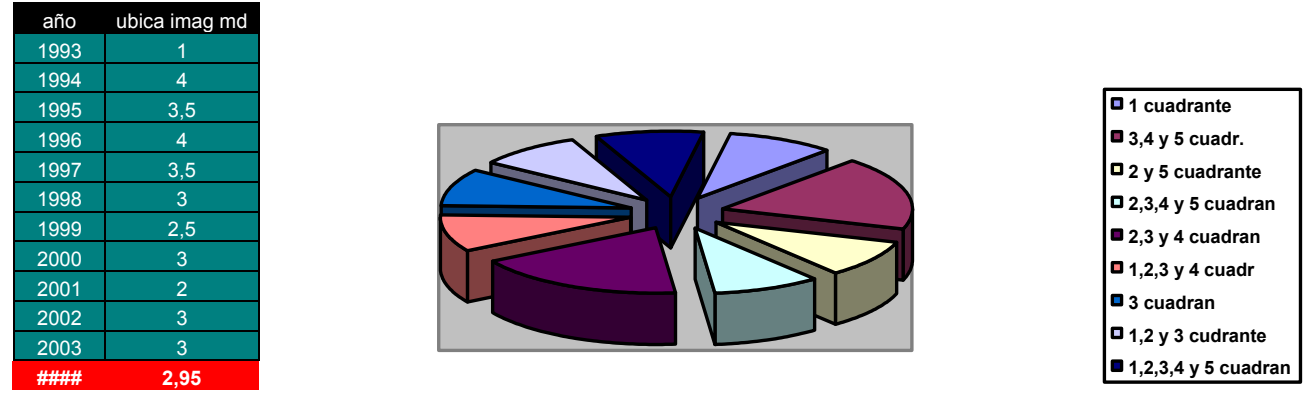

Con respecto a la dirección de las piezas, existe una clara tendencia en los mensajes gráficos, en la categoría de vehículos y accesorios, del Festival de San Sebastián a las direcciones de piezas diagonales. Aunque las frecuencias generales en los años investigados prevalezcan en número a la dirección vertical y horizontal. Las direcciones diagonales buscan una mayor implicación activa en el receptor. Son mensajes con más riesgo comunicativo y con más tensión.

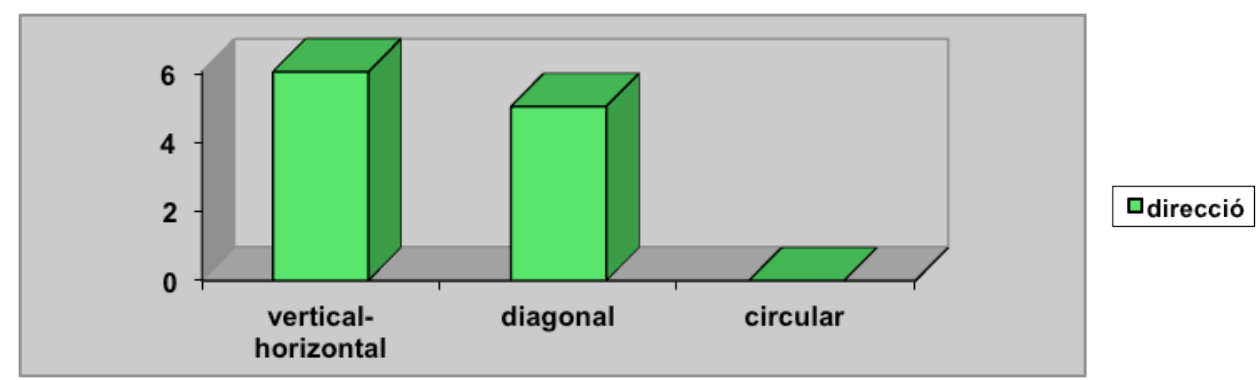

Con respecto al formato ratio no podemos llegar a profundas conclusiones debido a la preponderancia del formato corto; $81,81 \%$ sobre el largo; $18,18 \%$. Los anunciantes tienden es su gran mayoría de piezas a crearlas con formato largo sobre el corto. Además, las apariciones del formato corto han aparecido cíclicamente y no existe ninguna relación que justifique su aparición. 

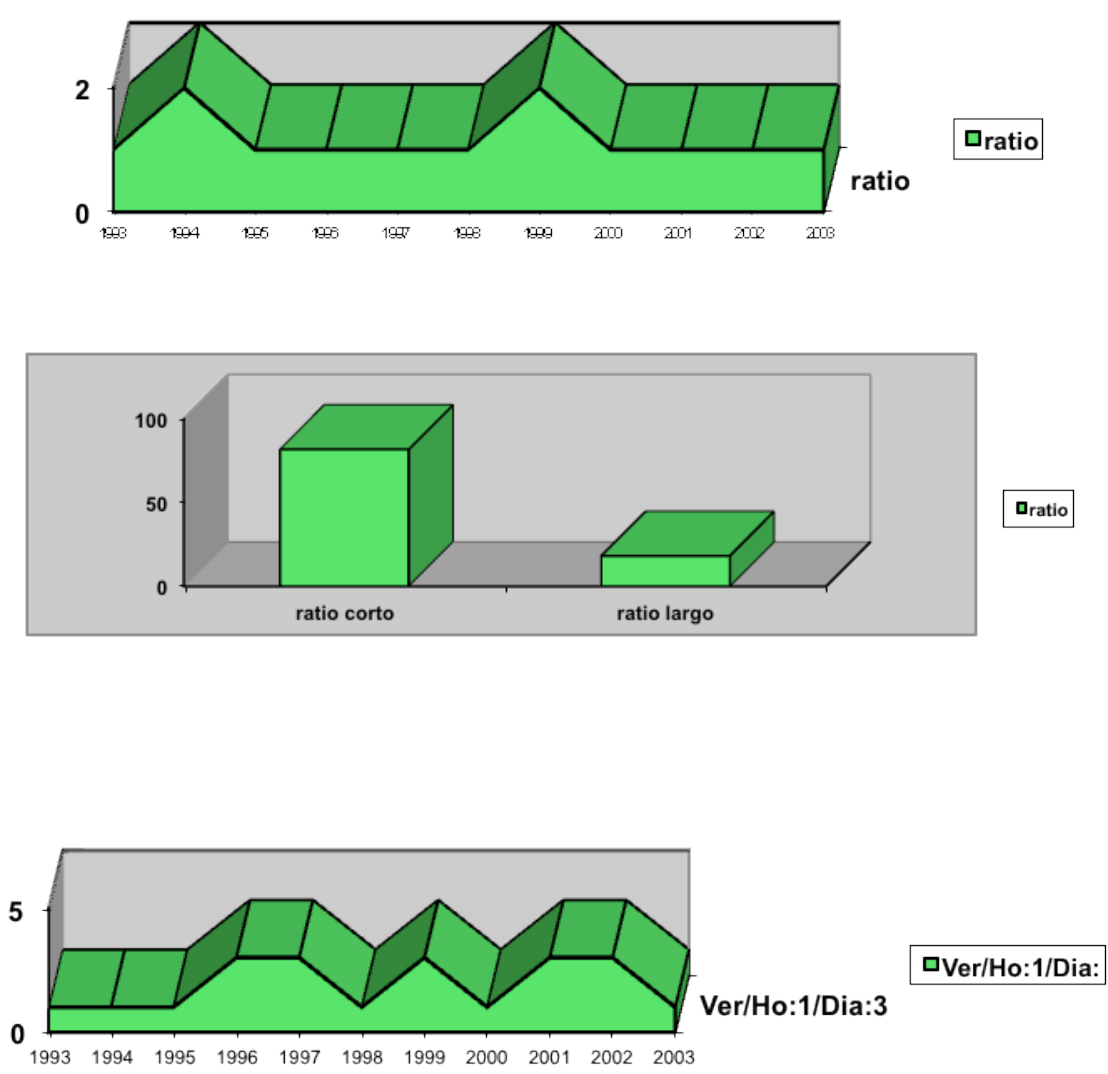

\section{BIBLIOGRAFÍA}

BAER, R. (2003). Mindfulness training as a clinical intervention: A conceptual and empirical review. Clinical Psychology: Science and Practice.

BARNES-HOLMES, D., BARNES-HOLMES, Y., MCHUGH, L. Y HAYES, S. C. (2004). Relational FrameTheory: Some implications for understanding and treating human psychopathology.

BASSAT, Luis, (2001), El libro Rojo de la Publicidad. Plaza \& James Editores, S.A. Barcelona.

BENAVIDES DELGADO, Juan, (1994), La crisis de la publicidad, Madrid, Editorial Comunicación 2000.

BROWN, K. W. Y RYAN, R. M. (2003). The bennefits of being present: Mindfulness and its role in psychological well-being. Journal of Personality and Social Psychology,

BUNGE, Mario (1981): La investigación científica. Ariel. Barcelona.

BUTLER-BOWDON, T. (2007). Cincuenta clásicos espirituales. Barcelona: Amat.

CALDEVILLA DOMINGUEZ, David (2004): Relaciones Públicas y su fundamentación. 
Vision Net. Madrid.

CLEMENTE, Miguel y SANTALLA, Zuleyma, (1991), El Documento Persuasivo. Universidad Complutense de Madrid. Bilbao, Ediciones Deusto S.A.

DONDIS, D.A. (1985), La sintaxis de la imagen : introducción al alfabeto visual, Barcelona, Gustavo

Gili.

FERRAZ MARTÍNEZ, Antonio, (2001), El lenguaje de la publicidad, Madrid, Arco Libros.

JOANNIS, Henri, (1992), El proceso de creación Publicitaria, Planteamiento, concepción y realización de los mensajes, Bilbao, Ediciones Deusto

JOANNIS, Henri, (1996) La creación Publicitaria desde la Estrategia de Marketing. Bilbao. Editorial Deusto.

LEÓN, José Luis, (1996), Los efectos de la publicidad, Madrid, Editorial Ariel.

MOLINÉ, Marçal, (2003), La comunicación activa. Publicidad sólida, Barcelona, Editorial Deusto.

VARGAS, José Jesús, (2012), Análisis de la Comunicación publicitaria gráfica: Deconstrucción de la eficiencia comunicativa gráfica: innovador método docente en el análisis y construcción de los mensajes publicitarios. Editorial: Vision Libros. Madrid.

WILSON K. G. Y LUCIANO M. C. (2002). Terapia de aceptación y compromiso (ACT). Un tratamiento conductual orientado a los valores. Madrid: Pirámide.

ZUNZUNEGUI, (1984), Mirar la imagen, Bilbao, Universidad del País Vasco.

\section{José Jesús Vargas Delgado}

Decano de la Universidad Europea de Canarias (UEC) en la Villa de la Orotava. Director del Departamento de Publicidad y Contenidos, y Director del Departamento de Comunicación Corporativa en la Universidad Europea de Madrid (UEM) desde 2002, con más de 15 años de trayectoria en la UEM. Doctor acreditado, en Creatividad Publicitaria Gráfica. Autor, entre otros, del libro Análisis de la comunicación publicitaria gráfica: Deconstrucción de la eficiencia comunicativa gráfica. Doctorado en Estudios Superiores sobre la Unión Europea. Licenciado en Publicidad y Relaciones Públicas por la Universidad Complutense de Madrid. Desde el año 2002 ha colaborado con múltiples proyectos turísticos, con la empresa Antar Estrategias. Profesor, desde el año 1999 hasta la actualidad, de las asignaturas: Teoría de la Publicidad y RRPP, Investigación de Mercados, Pensamiento Creativo, Políticas de Comunicación, Teoría de la Comunicación, Estructura del Sector Publicitario, Comunicación Persuasiva, Kundalini Yoga, Técnicas de Relajación, Promoción de Ventas, Técnicas de Ventas, 
Psicología del Consumidor, Marketing aplicado a la Publicidad, Teoría de los Medios de Comunicación, Creatividad Publicitaria. Profesor en el Máster de Marketing de la Universidad Camilo José Cela. Docente en el Máster en Creación de Contenidos de Telecinco. Profesor del Máster MFA (Master Of Fine Arts) en Tracor. Docente del Máster de Psicología del Consumidor en la Universidad de Granada. Profesor de Publicidad y Psicología en el Instituto Europeo de Marketing y Comunicación (IECM). Conferenciante en numerosos congresos. Miembro del equipo investigador del proyecto Tesoros vivos de la televisión (Academia de la Televisión y la UEM). Además de la investigación en Comunicación Publicitaria Gráfica, su área de estudio se centra en la novedosa vinculación de técnicas alternativas como Maestro de meditación, basadas en la relajación y consciencia, (Kundalini Yoga, Reiki y Mindfulness) como estimulación, y fomento, de la creatividad y evolución personal, y profesional, del individuo. 